\title{
Reverse triage: more than just another method
}

Gwen POLLARIS ${ }^{\mathrm{a}}$ and Marc SABBE

aDepartment of Emergency Medicine, University Hospitals Leuven, Leuven, Belgium

Running title: Reverse triage

Correspondence to:

Gwen Pollaris

Department of Emergency Medicine

University Hospitals Leuven

Herestraat 49

Leuven B-3000

Belgium

Tel: (016) 343900 Fax: (016) 343899

Email: gwen.pollaris@uzleuven.be 


\section{Abstract}

Introduction: Reverse triage is a way to rapidly create inpatient surge capacity by identifying hospitalised patients who do not require major medical assistance for at least 96 hours and who only have a small risk of serious complications due to early discharge. Methods: Electronic searches were conducted in the databases of MEDLINE, TRIP, the Cochrane Library, CINAHL, EMBASE, WEB OF SCIENCE and SCOPUS to identify relevant publications published from 2004 to 2014 . The reference lists of all relevant articles were screened for additional relevant studies that might have been missed in the primary searches. Results: There always will be small individual differences in the reverse triage decision process influencing the potential effect on surge capacity but at most, $10 \%$ to $20 \%$ of hospital total bed capacity can be made available within a few hours. Reverse triage could be a response to ED crowding as it gives priority to ED patients with urgent needs over inpatients who can be discharged with little to no health risks. The early discharge of inpatients entails negative consequences. They often return to the ED for further assessment, treatment, and even readmission. When time to a medical referral or bed is less than 4 to 6 hrs respectively, 100 additional lives per annum are predicted to be potentially saved. Discussion: The results of our systematic review identified only a small number of publications addressing reverse triage, indicating that reverse triage and surge capacity are relatively new subjects for research within the medical field. Not all research questions could be fully answered.

Keywords: triage, mass casualty incidents, emergency service hospital, surge capacity, patient discharge 


\section{Introduction}

Mass casualty incidents ( $\mathrm{MCls}$ ) can no longer be ignored in today's society. They lead to unexpected and sudden increases in patient volume at hospitals. This major influx can easily overwhelm an emergency department (ED) and even the entire hospital's capacity and resources. A health-care system's ability to rapidly expand their normal capacity to meet the increased demand is called surge capacity [1]. If full surge capacity is not achieved quickly, ED crowding will occur, leading to a decrease in the overall quality of delivered patient care [2-4]. For most situations, it is assumed that hospitals should be able to sustain medical services for up to 96 hours without external aid. To ensure this, methods to improve surge capacity are being developed [5]. One of these methods-called reverse triage-addresses both problems by simultaneously creating additional surge capacity and reducing crowding. The term reverse triage originates from the military. This approach prioritises treating the least wounded soldiers first so they can recover and return to the battlefield as soon as possible. The civilian model of reverse triage suggests a similar approach, one in which patients who need the least amount of medical assistance are prioritised so that they can be discharged as soon as possible [5]. Implementing reverse triage in the civilian model is a way to rapidly create inpatient surge capacity by identifying hospitalised patients who do not require major medical assistance for at least 96 hours and who only have a small risk of serious complications due to early discharge. Such patients can be immediately discharged in MCls so that disaster victims, who are in greater need of hospital care and resources, can receive priority [6-10]. Low-risk patients can be discharged home or to less acute-care facilities (e.g., nursing homes or public health contingency stations) [5]. When patients have been downgraded to an on-site nursing facility, paramedic personnel could support nurses by helping with the patients' activities of daily living, medication distribution, and wound care [6]. There is also a moral principle relevant to reverse triage that guides allocation of inpatients in a disaster surge situation. This moral framework captures the idea that '... patients must be considered as individuals competing on equal terms for the limited resources available and are judged in purely clinical terms' [10]. Some authors believe this principle - to achieve the most good for the greatest number of patients-can be 
used not only in extraordinary situations but also in daily practice as ED crowding is an increasing problem $[11,12]$. Proponents believe it is justifiable to reduce ED crowding by prioritising ED patients who need urgent medical attention at the expense of inpatients [10]. Others are more reticent to apply reverse triage to everyday hospital surge. In an $\mathrm{MCl}$, a certain range of risks are deemed acceptable that would otherwise be intolerable. This is why cut-offs for receiving medical attention need to be reconsidered, because they are probably going be lower than those tolerated during a disaster [3]. We conducted a systematic literature search to provide an overview of existing evidence about reverse triage, to better understand its limitations, and to draft goals for further research. The following research question was used as a guide throughout the review: During an $\mathrm{MCl}$, what is the association between reverse triage implementation in adult inpatients and (1) hospitals' surge capacity, (2) ED crowding, (3) prevalence of adverse events after early discharge, and (4) mortality rates? 


\section{Methods}

\section{Data sources and searches}

Electronic searches were conducted in the databases of MEDLINE, TRIP, the Cochrane Library, CINAHL, EMBASE, WEB OF SCIENCE and SCOPUS to identify relevant publications published from 2004 to 2014. For MEDLINE, we used the following MeSH terms: "Mass Casualty Incidents", "Triage", "Emergency Service, Hospital", "and Surge Capacity ", reverse triage "," Patient Discharge "," Disaster Planning, Emergency Medical Services "," Crowding" and "patient relocation". The following keywords were used for searching the other databases: for TRIP, "reverse triage", "mass casualty incident", "triage", "surge capacity", "patient relocation", "emergency department", "overcrowding", "crowding", "early discharge", "guidelines", and "discharge"; for The Cochrane Library, "reverse triage", "triage", "surge capacity", "crowding" and "mass casualty incidents"; for CINAHL, "triage", "surge capacity", "mass casualty incidents", "early patient discharge", "reverse triage", "emergency service", "overcrowding", "crowding" and "practice guidelines"; for EMBASE, "reverse triage", "surge capacity", "early discharge", "mass casualty event", "crowding" and "mortality"; for WEB OF SCIENCE, "reverse triage", "crowding", "emergency department", "early discharge", " inpatients", "surge capacity", "mortality", "mass casualty incidents" and "adverse events"; for SCOPUS, "reverse triage", "crowding", "adverse events", "surge capacity", "mass casualty incidents", "emergency department", early discharge", "inpatients" and "mortality". The reference lists of all relevant articles were screened for additional relevant studies that might have been missed in the primary searches.

\section{Inclusion and exclusion criteria}

To be included for further analysis, publications had to meet several criteria. First, the population studied were hospitalised adult patients preferably during an $\mathrm{MCl}$, the intervention applied was reverse triage, and the outcomes assessed were surge capacity of the hospital, ED crowding, adverse events in early-discharged patients, and effect on mortality rate. Finally, a ten-year time constraint and 
the study had to be published in English, Dutch, or French. Publications that did not meet all these inclusion criteria were excluded for consideration.

\section{Critical appraisal of studies}

Different sources were used to evaluate the quality of the reviewed literature. Appraisals of the experimental studies, systematic reviews, and cohort studies were guided by assessment forms from the Dutch Cochrane Centre [13]. Each of these forms was developed to assess the overall quality of a specific study design. The assessment form for experimental studies considered the following aspects: randomisation, concealment of allocation, blinding (of outcome assessor, treatment provider, and patient); comparability of the groups, selective loss to follow-up, intention-to-threat analysis, and comparability of the treatment. Systematic reviews were assessed for other particular aspects not included in the Cochrane assessment forms. These were a clearly defined research question, search strategy, study selection, quality assessment, data extraction, study characteristics, and meta-analysis. For the quality assessment of cohort studies, the following areas were evaluated: clearly defined cohort group, absence of selection bias, clearly defined exposure and assessment method, clearly defined outcome and assessment method, blinded outcome measurement, follow-up period appropriate for the aim of the study, absence of selective loss to follow-up, confounding variables described. The retrospective observational studies were assessed using the revised and validated version of Methodological Items for Non-randomised Studies (MINORS) [14]. These include clearly stated aim, inclusion of consecutive patients, prospective collection of data, endpoints appropriate to the aim of the study, unbiased assessment of the study endpoint, follow-up period appropriate for the aim of the study, loss to follow-up less than $5 \%$, and prospective calculation of the study size. The appraisal questions were rated ' + ' if the criterion was reported adequately or fulfilled, ' $+/-$ ' when the criterion was reported but inadequately fulfilled, and '-' if the criterion was not met or not reported. 


\section{Results}

\section{Article selection}

The electronic literature search using the keywords returned a total of 3021 hits (Fig. 1). Screening of abstracts and titles excluded 2869 publications from this list. Another 134 duplicates were excluded, resulting in 18 relevant articles. We identified four additional relevant publications in the reference lists of the included articles. This produced a subtotal of 22 potentially relevant articles. By reviewing the entire text of the selected publications, we were able to exclude five more articles: four failed to describe an outcome of interest and one article reported on a paediatric population. This resulted in a total of 17 relevant articles to be included. Ten articles reported on studies conducted in the United States of America (USA) [1, 5-7, 9, 10, 15-18]; three in Australia $[3,8,11]$; one in the United Arab Emirates (UAE) [19]; one in Ireland [4] and two in the United Kingdom (UK) [2, 12]. Noticeably, only three articles dealt with a European study [2, 4, 12].

\section{Quality assessment of reviewed articles}

Seven retrospective observational studies were included in this review $[4,6,8,9,15,19,12]$; one prospective cohort study [16]; two experimental studies, one of which was a randomised controlled trial (RCT) [7] and one study with a pre-experimental time-series design [17]; three systematic reviews about related subjects $[1,2,10]$; and four consensus statements were included $[3,5,11,18]$. The quality of the retrospective observational studies (Table 1 ) was suboptimal. All observational studies failed to mention two of the eight quality assessment criteria: the potentially 'unbiased assessment of the study endpoint' and the 'prospective calculation of the study size'. Furthermore, most studies received several '+/-' in their MINORS assessment.

In contrast, the overall quality of the prospective cohort study [16] was acceptable. It only lacked two criteria ('blinded outcome measurement' and 'no selective loss-to-follow-up'), scoring ' + ' on the remaining six items (Table 2). The RCT did not fully meet the quality assessment criteria. Of the nine criteria for RCTs, only two received a ' + ', one received a ' $+/-$ ', and six received a '-' (Table 3 ). The study 
that used a time-series, one-group pretest-posttest design, did not score well either [17]. The assessment score of this low-quality experimental design will be low as it was assessed using the same criteria to assess the RCT, which was a higher quality experimental design. This study scored a '+/-' on three criteria and a '-' on the remaining criteria (Table 3).

The three systematic reviews also were of limited quality. They all scored a '-' on 'quality assessment' and 'meta-analysis' and a ' $+/-$ ' on 'clearly defined research question' and 'data extraction'. The results of the remaining three criteria differed (Table 4). Of the consensus statements, no quality assessment could be assessed because consensus statements are defined as having the lowest quality level of evidence $[3,5,11,18]$.

\section{Reverse triage and surge capacity}

Most of the studies included in our review examined bed clearance over a 96-hour period. This assessment period is based on data from the USA, which is the expected interval a hospital can cope with surge without external aid [7]. At most, $10 \%$ to $20 \%$ of hospital total bed capacity can be made available within a few hours using reverse triage [1]. In the study conducted in the UAE, reverse triage identified approximately 75 patients who met criteria for early discharge. Sixty beds were cleared within eight hours, representing $80 \%$ of the total identified patients and $12 \%$ of the total hospital bed capacity [18]. Three studies dealing with medical surge were conducted in the USA. In one study done at a large academic centre having a total capacity of 900 beds, 205 patients were observed for 72 hours and $47.8 \%$ of them were ultimately discharged [9]. The hospital normal daily discharges represented $14.5 \%$ of its total capacity. Also, implementing a safe early-discharge protocol could create an additional 65 beds [9]. The second study included 788 patients from four different hospitals. Of these, $119(15 \%)$ could potentially be discharged in 2 hours, $243(31 \%)$ in 24 hours, and 392 (50\%) in 72 hours [6]. In the third American study, the potential surge capacities of an academic, an affiliate, and a community hospital were, respectively, 33\% (95\% Cl 29\%-36\%), 39\% (95\% Cl 33\%-45\%), and 48\% (95\% Cl 41\%-56\%) of beds, which could be made available by implementing an early discharge protocol [7]. Reverse triage created the greatest additional capacity in each facility, yielding $50 \%, 55 \%$, and $59 \%$ of 
beds, respectively [7]. An Australian observational study assessed the response to an $\mathrm{MCl}$, forced to treat up to 30 casualties [8]. Reverse triage was applied and 56 beds were predicted to be available within four hours ( $16 \%$ of total capacity). At that time, almost half of these patients had no impact on the available beds, as they were in the hospital as day cases or for renal dialysis. Thus, in reality, only 19 beds were directly claimable [8]. Finally, a UK study assessed its theoretical discharge capacity in a tertiary teaching hospital, with a total capacity of 855 beds [12]. They repeated surveys over 12 days in three months. Immediately at the start of the surveys a mean of 78 beds were made available. One to four hours later, an additional 69 beds became available, and 4 to 12 hours later an additional 155 beds became available, producing a total of 302 beds ( $36 \%$ of total capacity) within 12 hours. This was achieved by doing more than just accelerating the discharge process. Elective surgeries were also cancelled, resulting in an inevitable discharge of all preoperative patients [12]. Note, the discharges and cancelations did not actually happen, it was a theoretical assessment of the hospital's surge capacity. Naturally, there always will be small individual differences in the reverse triage decision process, influencing the potential effect on surge capacity. One study showed a significant difference between nurse managers and physicians. At four different hospitals, nurse managers and physicians from each inpatient unit were assigned to make assessments of each patient's predicted disposition at $2,24,48$, and 72 hours in case of an $\mathrm{MCl}$. The results demonstrated that physicians were more likely than nurse managers to transfer patients to a lower level of care. However, the complete opposite was in case of ICU patients: physicians were less likely than nurse managers to transfer patients out of the ICU. This reached a significant difference at two hours $(p<0.001)[6]$. 


\section{Reverse triage and ED crowding}

ED crowding is caused by many operational inefficiencies, most important, the restricted access to inpatient beds. This leads to boarding admitted patients at the ED. Reverse triage could be a response to this form of ED crowding as it gives priority to ED patients with urgent needs over inpatients who can be discharged with little to no health risks [10]. This is guided by the principle-based approach of bioethical theory for emergency physicians. It describes the fundamental ethical duties of emergency physicians according to four main principles: (1) autonomy (informed consent of the patient), (2) beneficence (balancing risks and benefits of an action), (3) nonmaleficence (avoiding causation of harm), and (4) justice (distributing risks and benefits fairly among patients) [10]. Furthermore, the hospital may not enforce strict discharge criteria, as it would result in an infringement of the independent clinical judgment of physicians [10].

\section{Reverse triage and prevalence of Adverse Events}

Reverse triage is associated with the early discharge of inpatients. Unfortunately this also entails some negative consequences. Early-discharged patients often return to the ED for further assessment, treatment, and even readmission, further contributing to and worsening the ED crowding. These patients use already limited hospital resources, materials, staff, knowledge, and other assets that are now unavailable to other patients. In one study, 6290 ED visits were logged during a one-month followup period, and 174 of these were return visits (3\%) [15]. Of these return patients, 82 (47\%) were admitted, comprising 7\% of the total ED admissions for that period. Compared to other ED patients, these 174 return patients spent more time in treatment (6.58 hours vs. 5.22 hours) and were more than twice as likely to be admitted ( $47 \%$ vs. $19 \%)$. This finding supported the authors' hypothesis that resource use is much higher for return patients. Remarkably, 16 of the 174 return patients had a related and likely preventable problem [15]. Because early-discharge patients may still have functional impairments and because they may experience discontinuity in care as they transition, they are especially vulnerable to injuries [16]. A prospective cohort study conducted in the USA followed 400 
patients for three weeks after discharge [16]. Seventy-six patients experienced symptoms related to injuries from medical care. Thus, the incidence of adverse events was 19\% (95\% Cl 15\%-23\%). Sixty-six percent (95\% Cl 55\%-76\%) were adverse drug events, 17\% (95\% Cl 8\%-26\%) were procedure related, and a few resulted from nosocomial infections and falls. Forty-nine patients (64\%) experienced symptoms (e.g., rash, insomnia) for several days. Twenty-three patients (30\%) experienced temporary disabilities (e.g., severe dehydration due to Clostridium difficile infection), and two patients (3\%) had permanent disabilities. Of the 400 patients, $11 \%$ 'bounced back' to an ED, and $24 \%$ were readmitted [16].

To reduce these negative outcomes, a disposition classification system based on a risk assessment of consequential medical events (CME) as a result of early hospital discharge has been developed [5]. To be considered consequential, events had to arise within 72 hours after discharge and would have been stabilised or ameliorated by an adequate in-hospital intervention (e.g., unexpected death, irreversible impairment, or functional reduction). The classification system comprises five categories, with an agreed-upon upper limit of acceptable risk for declaring an onset of a CME. The first category includes patients having a minimal possibility of developing a CME 72 hours after discharge to home; this category has a 3.8\% (IQR 2-5) upper limit of risk tolerance. The second class includes patients who should be transferred to a low acuity facility instead of remaining in their current location; this category has an upper limit of $11.7 \%$ (IQR 8-15). The third category includes patients who should be transferred to another medical facility with moderate capabilities, as a CME is likely to occur if critical intervention is delayed; this category has an upper limit of risk tolerance of $33.1 \%$ (IQR 25-50). The fourth category includes patients who are likely to need continued highly skilled care and acute-hospital resources; this category has an upper limit of $61 \%$ (IQR 45-80). Lastly, the fifth category of the disposition classification system includes patients who cannot be transported because they are too unstable; this category has the highest risk tolerance of 92.3\% (IQR 95-100) [5]. The expert panel developing this system decided to maintain a risk tolerance limit for adverse events up to $12 \%$, if necessary $[5,7]$. 


\section{Reverse triage and mortality}

The study of Plunkett et al (2011) states that the 30-day inhospital mortality rates increase with 53\% once patient processing time in the ED moves beyond four hours. Based on this mortality data and the number to treat, given by their earlier study, they predict 100 additional lives per annum could be saved when time to a medical referral is less than four hours and maximal time to a bed less than six hours [4]. This is not proved by either empirical or experimental evidence. 


\section{Discussion}

The results of our systematic review identified only a small number of publications addressing reverse triage, indicating that reverse triage and surge capacity are relatively new subjects for research within the medical field. Nevertheless, the evidence revealed some important findings.

First, reverse triage is a sure way to rapidly create inpatient surge capacity by identifying inpatients who do not require major medical assistance for at least 96 hours and who have a small risk of serious complications due to early discharge [6-10]. Second, small individual differences in the reverse triage decision process exist. For example, one study discovered a significant difference between nurse managers and physicians. Physicians were more likely to transfer patients to a lower level of care [6]. Third, depending on the country, hospitals were expected to manage without external aid for approximately 48 to 96 hours in an $\mathrm{MCl}$ situation [5, 7]. Fourth, how much surge capacity a hospital should be expected to produce, a priori, remains unclear. Because no universal rules are in place on how to quantify or describe the achieved surge capacity, comparison between countries is not reasonably possible at this time [11].

Fifth, reverse triage could be a response to ED crowding as it gives priority to ED patients with urgent needs over inpatients who can be discharged with little to no health risks [10]. Sixth, the present article originally intended to focus on implementing reverse triage in times of extraordinary surge. But as became clear in the review of the literature, reverse triage also can be used to cope with daily surge (crowding). Unfortunately, international agreement about using reverse triage as a crowding countermeasure does not exist presently.

Seventh, implementing the reverse triaging process is not without inherent risks. It can produce 'bounce-back' patients and adverse events [15]. For example, in a one-month observational study, 174 return visits were registered, which was $3 \%$ of the total ED discharges. Of these, $47 \%$ were readmitted, comprising $7 \%$ of the total ED admissions for that period. Remarkably, 16 patients had a related and likely preventable problem [15]. In another study, nearly one-fifth of patients experienced an adverse 
event after discharge, in which one-third of these were preventable and another one-third was ameliorable. Injuries ranged from serious laboratory abnormalities to permanent disabilities [16].

Eighth, by facilitating the early discharge of inpatients, reverse triage could decrease the delay to admission with a maximum time to bed of six hours and even contribute to ameliorate the time to a medical referral, as it reduces ED crowding. Based on this mortality data and the number to treat, given by their earlier study, the study of Plunkett et al (2011) predicts 100 additional lives per annum could be saved when time to a medical referral is less than four hours and maximal time to a bed less than six hours [4]. This is not proved by either empirical or experimental evidence. The literature did not mention any publications concerning mortality rates after early discharge for all patients in general, only for specific populations (e.g. patients with a hip fracture). Because of the low generalizability, these publications were not included.

\section{Limitations}

First of all, 4 of the 16 included articles were based on consensus statements. Second, due to the absence of empirical data, most studies were based on simulated exercises, which may not reflect reality. Third, some authors did not describe the used methods to carry out their study [6], thereby diminishing the quality of their results. Fourth, most of the estimates were made by the included studies based on normal daily discharge rates in combination with cross-sectional data obtained through the study. This method is inadequate, because the actual number of patients who could be discharged early is underestimated [6]. Furthermore, there are more ways to create additional bed capacity than just discharging inpatients (e.g., transfer to a step-down facility), but only one study investigated this possibility [6]. Another reason why this method is inadequate is that many hospitals have available beds in areas that are not included in hospitals capacity estimates, because they are not staffed on a daily basis [6]. If additional paramedical and/or medical personnel were made available or 
if staff were moved from their normal posts to these areas, these beds could be useful. Lastly, only one study investigated the impact of triage personnel on patient disposition [6].

\section{Conclusions}

Coping with surge capacity, whether it be daily or extraordinary, is an emerging problem for which reverse triage may offer a solution. Unfortunately, published literature on the utility and effects of reverse triage on managing medical surge is scarce and full of important limitations. Further research is crucially needed to determine whether reverse triage can be used to cope with daily surge and to create universally applicable, international standards for determining the measurable outcomes and prognostic variables for conducting reverse triage [5]. Uniform standards for reporting achieved surge capacity currently do not exist. Once this guideline is established, it would be useful to develop a reverse triage system implemented electronically, which incorporates the above-mentioned prognostic variables and other medical data (e.g., patients' vital signs) to provide a real-time overview of inpatients' medical status. This would facilitate clinical decision-making processes related to reverse triage [5]. 


\section{References}

1. Nager AL, Khanna K. Emergency Department Surge: Models and Practical Implications. J Trauma 2009; 67: S96-S99.

2. Collis J. Adverse effects of overcrowding on patient experience and care. Emerg Nurse 2010; 18: 34-39.

3. Taylor D. Reverse triage: useful for day-to-day acces block? Lancet 2006; 368: 1940-1941.

4. Plunkett PK, Byrne DG, Breslin T, Bennett K, Silke B. Increasing wait times predict increasing mortality for emergency medical admissions. Eur J Emerg Med 2011; 18(4): 192-196.

5. Kelen GD, Kraus CK, McCarthy ML, Bass E, Hsu EB, Li G, et al. Inpatient disposition classification for the creation of hospital surge capacity: a multiphase study. Lancet 2006; 368: 1984-1990.

6. Davis DP, Poste JC, Hicks T, Polk D, Rymer TE, Jacoby I. Hospital Bed Surge Capacity in the Event of a Mass-Casualty Incident. Prehosp Disaster Med 2005; 20: 169-176.

7. Kelen GD, McCarthy ML, Kraus CK, Ding R, Hsu EB, Li G, et al. Creation of Surge Capacity by Early Discharge of Hospitalized Patients at Low Risk for Untoward Events. Disaster Med Public Health Prep 2009; 3: S1-S7.

8. Satterthwaite PS, Atkinson CJ. Using 'reverse triage' to create hospital surge capacity: Royal Darwin Hospital's response to the Ashmore Reef disaster. Emerg Med J. 2010.

9. Kelen GD, Kraus CK, Brill JD. Creation of Hospital Surge Capacity by the Early Discharge of Inpatients. Acad Emerg Med 2005;12: 23.

10. Moskop JC, Sklar DP, Geiderman JM, Schears RM, Bookman KJ. Emergency Department Crowding, Part 2- Barriers to Reform and Strategies to Overcome Them. Ann Emerg Med 2009. 53:612-617.

11. Bradt DA, Aitken P, FitzGerald G, Swift R, O'Reilly G, Bartley B. Emergency Department Surge Capacity: Recommendations of the Australian Surge Strategy Working Group. Acad Emerg Med 2009; 16: 1350-1358.

12. Challen K, Walter D. Accelerated discharge of patients in the event of a major incident: observational study of a teaching hospital. BMC Public Health 2006; 6: 108. 
13. Dutch Cochrane Centre. http://dcc.cochrane.org/beoordelingsformulieren-en-andere-downloads (accessed 18 April 2014).

14. Slim K, Nini E, Forestier D, Kwiatkowski F, Panis Y, Chipponi J. Methodological Index for Nonrandomized Studies (Minors): Development and Validation of a New Instrument. ANZ J Surg 2003; 73: 712-716.

15. Baer RB, Pasternack JS, Zwemer FL. Recently Discharged Inpatients as a Source of Emergency Department Overcrowding. Acad Emerg Med 2001; 11: 1091-1094.

16. Forster AJ, Murff HJ, Peterson JF, Gandhi TK, Bates DW. The Incidence and Severity of Adverse Events Affecting Patients after Discharge from the Hospital. Ann Intern Med 2003; 138: 161-167

17. Nash K, Nguyen H, Tillman M. Using Medical Screening Examinations to Reduce Emergency Department Overcrowding. J Emerg Nurs 2009; 35: 109-113.

18. Dunford D. Screening Out Does Little to Address ED Overcrowding. J Emerg Nurs 2009; 35: 280.

19. Griffiths JL, Estipona A, Waterson JA. A framework for physician activity during disasters and surge events. Am J Disaster Med 2011; 6: 1-8. 


\section{Figures and tables}

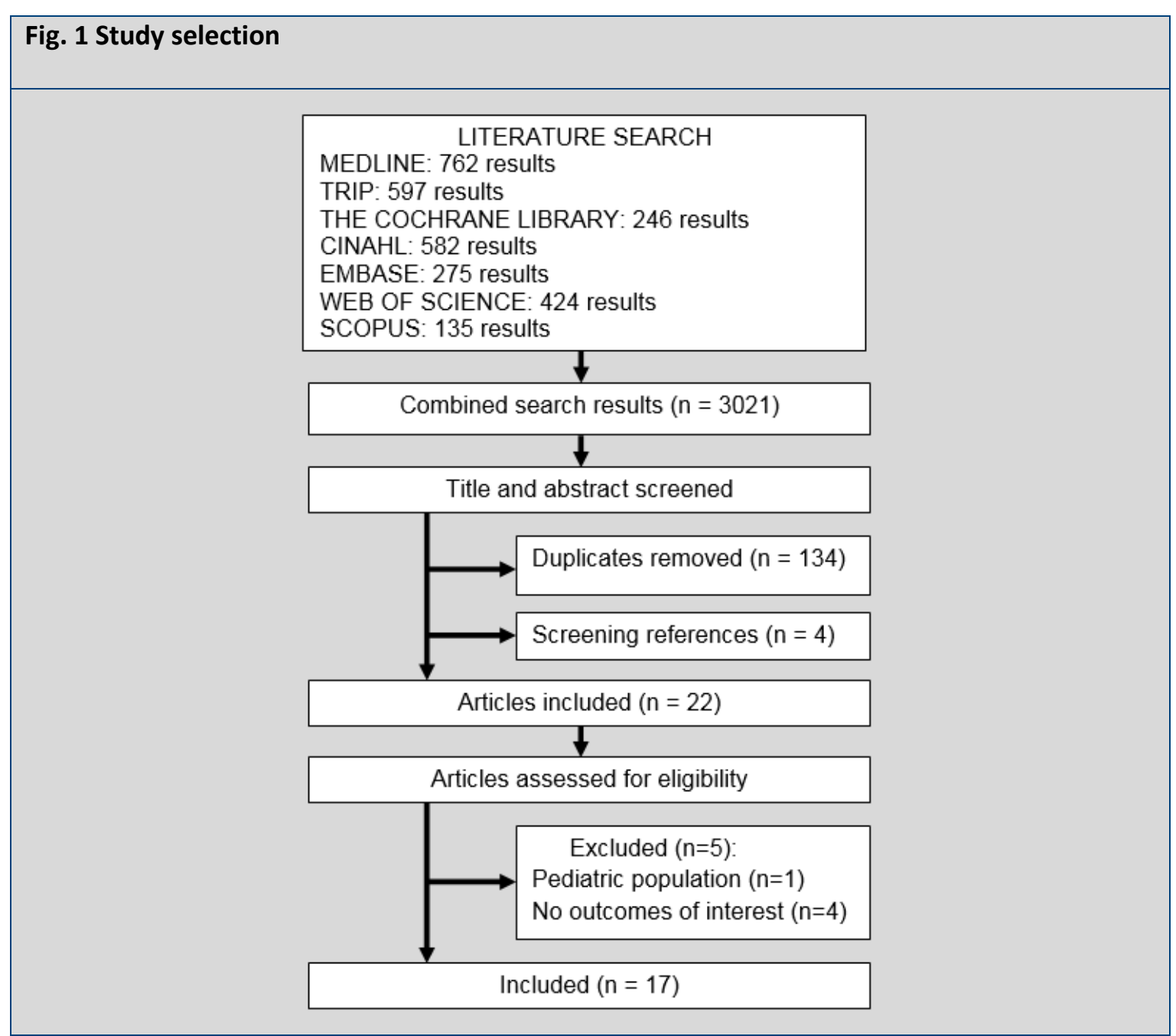




\begin{tabular}{|c|c|c|c|c|c|c|c|c|}
\hline Study & $\begin{array}{l}\text { A clearly stated } \\
\text { aim }\end{array}$ & $\begin{array}{l}\text { Inclusion of } \\
\text { consecutive } \\
\text { patients }\end{array}$ & $\begin{array}{l}\text { Prospective } \\
\text { collection of } \\
\text { data }\end{array}$ & $\begin{array}{c}\text { Endpoints } \\
\text { appropriate to } \\
\text { the aim of the } \\
\text { study }\end{array}$ & $\begin{array}{l}\text { Unbiased } \\
\text { assessment of } \\
\text { the study } \\
\text { endpoint }\end{array}$ & $\begin{array}{c}\text { Follow-up } \\
\text { period } \\
\text { appropriate to } \\
\text { the aim of the } \\
\text { study }\end{array}$ & $\begin{array}{l}\text { Loss to follow- } \\
\text { up less than } 5 \%\end{array}$ & $\begin{array}{l}\text { Prospective } \\
\text { calculation of } \\
\text { the study size }\end{array}$ \\
\hline $\begin{array}{l}\text { Challen, Walter. } \\
(2006)[12]\end{array}$ & + & + & + & + & - & + & $+/-$ & - \\
\hline $\begin{array}{l}\text { Plunkett, Byrne, } \\
\text { Breslin , Bennett, } \\
\text { Silke. (2011) [4] }\end{array}$ & $+/-$ & + & - & + & - & + & - & - \\
\hline $\begin{array}{l}\text { Davis, Poste, Hicks, } \\
\text { Polk, Rymer, } \\
\text { Jacoby. (2005) [6] }\end{array}$ & + & $+/-$ & + & $+/-$ & - & + & $+/-$ & - \\
\hline $\begin{array}{l}\text { Baer, Pasternack, } \\
\text { Zwemer. (2001) [15] }\end{array}$ & + & + & - & + & - & + & - & - \\
\hline $\begin{array}{l}\text { Satterthwaite, } \\
\text { Atkinson. (2010) [8] }\end{array}$ & $+/-$ & $+/-$ & - & $+/-$ & - & + & - & - \\
\hline $\begin{array}{l}\text { Kelen, Kraus, Brill. . } \\
\text { (2005) [9] }\end{array}$ & + & $+/-$ & + & $+/-$ & - & + & - & - \\
\hline $\begin{array}{l}\text { Griffiths, Estipona, } \\
\text { Waterson. (2011) } \\
{[19]}\end{array}$ & + & - & - & $+/-$ & - & - & - & - \\
\hline
\end{tabular}

+ , Reported and adequate; +-, reported but inadequate; -, not reported. 


\begin{tabular}{|c|c|c|c|c|c|c|c|c|}
\hline Study & $\begin{array}{l}\text { Cohort group } \\
\text { clearly defined }\end{array}$ & $\begin{array}{l}\text { Selection bias } \\
\text { ruled out }\end{array}$ & $\begin{array}{l}\text { Exposure and } \\
\text { assessment } \\
\text { method clearly } \\
\text { defined }\end{array}$ & $\begin{array}{c}\text { Outcome and } \\
\text { assessment } \\
\text { method clearly } \\
\text { defined }\end{array}$ & $\begin{array}{c}\text { Blinded } \\
\text { outcome } \\
\text { measurement }\end{array}$ & $\begin{array}{c}\text { Follow-up } \\
\text { period } \\
\text { appropriate to } \\
\text { the aim of the } \\
\text { study }\end{array}$ & $\begin{array}{l}\text { Selective loss } \\
\text { to follow-up }\end{array}$ & $\begin{array}{c}\text { Confounding } \\
\text { variables }\end{array}$ \\
\hline $\begin{array}{l}\text { Forster, Murff, } \\
\text { Peterson, Gandhi, } \\
\text { Bates. (2003) [16] }\end{array}$ & + & + & + & + & - & + & - & + \\
\hline
\end{tabular}

+ , Reported and adequate; +-, reported but inadequate; -, did not meet the criterion. 


\begin{tabular}{|c|c|c|c|c|c|c|c|c|c|}
\hline Study & Randomisation & $\begin{array}{l}\text { Concealment } \\
\text { of allocation }\end{array}$ & $\begin{array}{l}\text { Blinding } \\
\text { of the } \\
\text { patients }\end{array}$ & $\begin{array}{l}\text { Blinding of } \\
\text { the } \\
\text { treatment } \\
\text { provider }\end{array}$ & $\begin{array}{l}\text { Blinding of } \\
\text { the outcome } \\
\text { assessor }\end{array}$ & $\begin{array}{l}\text { Comparability } \\
\text { of the groups }\end{array}$ & $\begin{array}{l}\text { Loss to } \\
\text { follow-up }\end{array}$ & $\begin{array}{l}\text { Intention-to- } \\
\text { threat } \\
\text { analysis }\end{array}$ & $\begin{array}{c}\text { Comparability } \\
\text { of the } \\
\text { treatment }\end{array}$ \\
\hline $\begin{array}{l}\text { Kelen, McCarthy, } \\
\text { Kraus, Ding, Hsu, Li, } \\
\text { et al. (2009) [7] }\end{array}$ & + & + & - & - & - & - & $+/-$ & - & - \\
\hline $\begin{array}{l}\text { Nash, Nguyen, } \\
\text { Tillman. (2009) }\end{array}$ & - & $+/-$ & $+/-$ & $+/-$ & - & - & - & - & - \\
\hline
\end{tabular}

+ , Reported and adequate; +/-, reported but inadequate; -, not reported. 


\begin{tabular}{|c|c|c|c|c|c|c|c|}
\hline Study & $\begin{array}{l}\text { Clearly defined } \\
\text { research question }\end{array}$ & Search strategy & Study selection & $\begin{array}{c}\text { Quality } \\
\text { assessment }\end{array}$ & Data extraction & $\begin{array}{l}\text { Characteristics of } \\
\text { included studies }\end{array}$ & Meta-analysis \\
\hline Collis (2010) [2] & $+/-$ & + & $+/-$ & - & $+/-$ & + & - \\
\hline $\begin{array}{l}\text { Moskop, Sklar, } \\
\text { Geiderman, Schears, } \\
\text { Bookman. (2009) } \\
{[10]}\end{array}$ & $+/-$ & - & - & - & $+/-$ & - & - \\
\hline $\begin{array}{l}\text { Nager, Khanna. } \\
\text { (2009) [1] }\end{array}$ & $+/-$ & + & $+/-$ & - & $+/-$ & - & - \\
\hline
\end{tabular}

+ , Reported and adequate; +/-, reported but inadequate; -, not reported. 